\title{
Influence of low ambient temperature on epitympanic temperature measurement: a prospective randomized clinical study
}

Giacomo Strapazzon ${ }^{1 *}$, Emily Procter ${ }^{1}$, Gabriel Putzer ${ }^{2}$, Giovanni Avancini' ${ }^{1}$ Tomas Dal Cappello1, Norbert Überbacher ${ }^{3}$, Georg Hofer ${ }^{4}$, Bernhard Rainer ${ }^{5}$, Georg Rammlmair ${ }^{6}$ and Hermann Brugger ${ }^{1}$

\begin{abstract}
Background: Epitympanic temperature $\left(T_{\text {ty }}\right)$ measured with thermistor probes correlates with core body temperature $\left(T_{\text {core }}\right)$, but the reliability of measurements at low ambient temperature is unknown. The aim of this study was to determine if commercially-available thermistor-based $T_{\text {ty }}$ reflects $T_{\text {core }}$ in low ambient temperature and if $T_{\text {ty }}$ is influenced by insulation of the ear.

Methods: Thirty-one participants (two females) were exposed to room $\left(23.2 \pm 0.4^{\circ} \mathrm{C}\right)$ and low $\left(-18.7 \pm 1.0^{\circ} \mathrm{C}\right)$ ambient temperature for 10 min using a randomized cross-over design. $T_{\text {ty }}$ was measured using an epitympanic probe (M1024233, GE Healthcare Finland Oy) and oesophageal temperature ( $\left.T_{e s}\right)$ with an oesophageal probe (M1024229, GE Healthcare Finland Oy) inserted into the lower third of the oesophagus. Ten participants wore ear protectors (Arton 2200, Emil Lux GmbH \& Co. KG, Wermelskirchen, Switzerland) to insulate the ear from ambient air.

Results: During exposure to room temperature, mean $T_{\text {ty }}$ increased from $33.4 \pm 1.5$ to $34.2 \pm 0.8^{\circ} \mathrm{C}$ without insulation of the ear and from $35.0 \pm 0.8$ to $35.5 \pm 0.7^{\circ} \mathrm{C}$ with insulation. During exposure to low ambient temperature, mean $T_{\text {ty }}$ decreased from $32.4 \pm 1.6$ to $28.5 \pm 2.0^{\circ} \mathrm{C}$ without insulation and from $35.6 \pm 0.6$ to $35.2 \pm 0.9^{\circ} \mathrm{C}$ with insulation. The difference between $\mathrm{T}_{\text {ty }}$ and $\mathrm{T}_{\mathrm{es}}$ at low ambient temperature was reduced by $82 \%$ (from 7.2 to $1.3^{\circ} \mathrm{C}$ ) with insulation of the ear.

Conclusions: Epitympanic temperature measurements are influenced by ambient temperature and deviate from $T_{\text {es }}$ at room and low ambient temperature. Insulating the ear with ear protectors markedly reduced the difference between $T_{\text {ty }}$ and $T_{\text {es }}$ and improved the stability of measurements. The use of models to correct $T_{\text {ty }}$ may be possible, but results should be validated in larger studies.
\end{abstract}

Keywords: Epitympanic temperature, Core body temperature, Thermistor thermometer, Non-invasive temperature measurement

\section{Background}

Accurate measurement of core body temperature $\left(\mathrm{T}_{\text {core }}\right)$ can be fundamental for guiding treatment and triage decisions in emergency care of patients. Although invasive techniques remain the gold standard for $\mathrm{T}_{\text {core }}$ measurement (pulmonary artery or lower third of the oesophagus) these sites are not practical in emergency situations [1].

\footnotetext{
* Correspondence: giacomo.strapazzon@eurac.edu

${ }^{1}$ EURAC Institute of Mountain Emergency Medicine, Bolzano, Italy

Full list of author information is available at the end of the article
}

Temperature at the tympanic membrane was originally proposed as a less invasive alternative for estimation of $\mathrm{T}_{\text {core }}[2,3]$. Previous investigations have shown that with precise placement in the lower anterior quadrant of the tympanic membrane, tympanic temperature is highly correlated with intracranial temperature and changes in temperature [4] and, importantly, that tympanic temperature is independent from the influence of changes in skin temperature [3]. Epitympanic temperature $\left(\mathrm{T}_{\text {ty }}\right)$ measured with a thermistor probe in the ear canal correlates with $\mathrm{T}_{\text {core }}$ in hypothermic patients $[5,6]$ and may be a non-invasive alternative for diagnosing the severity of 
hypothermia in victims of accidental hypothermia $[7,8]$. Case reports of deep hypothermic patients have shown that $\mathrm{T}_{\text {ty }}$ measured prehospitally was comparable to $\mathrm{T}_{\text {core }}$ measured invasively at hospital admission [9-11], but there is still a lack of data on the reliability of epitympanic measurements at low ambient temperature. Early studies compared $\mathrm{T}_{\text {ty }}$ to oesophageal temperature $\left(\mathrm{T}_{\text {es }}\right)$ during exposure to moderately low temperatures (between 0 and $\left.10{ }^{\circ} \mathrm{C}\right)[3,12,13]$, though ambient conditions in many prehospital situations are commonly much colder with confounding environmental factors. Only two case series (five participants each) describe $T_{\text {ty }}$ measured with self-made devices during cold exposure (between -20 and $-32{ }^{\circ} \mathrm{C}$ ) $[5,14]$. Pre-hospital use of commercially-available thermometers falls outside the tested operating conditions, since standard probes are validated in-hospital under relatively stable conditions [1]. The aim of this study was to determine if commercially-available thermistor-based $\mathrm{T}_{\text {ty }}$ reflects $\mathrm{T}_{\text {core }}$ in low ambient temperature and if $\mathrm{T}_{\mathrm{ty}}$ is influenced by insulation of the ear.

\section{Methods}

\section{Design, setting and participants}

Volunteers were recruited from the local mountain rescue organization. Written informed consent was obtained from all participants prior to participation in the study. The study was approved by the Ethics Committee of the Regional Hospital of Bolzano, Italy. Participants were in good cardiopulmonary health; a clinical history and medical examination were conducted to exclude acute or chronic conditions or abnormalities of the ear canal or upper airways. Cerumen was removed from the ear canal if necessary. Participants were instructed to fast for at least $6 \mathrm{~h}$ prior to testing.

We used a randomized cross-over design. Participants were randomly assigned to group A or B; group A was exposed to low temperature first followed by room temperature $(n=15)$; group B was exposed to room temperature first followed by low temperature $(n=16)$. A climate chamber with controlled temperature settings was used for the low temperature setting and a medical examination office for the room temperature setting.

\section{Monitoring}

An oesophageal probe (9F general purpose sterile probe M1024229, GE Healthcare Finland Oy) was inserted via the naris into the lower third of the oesophagus [15] after anesthesia of the nasal and pharyngeal mucosa with topical $2 \%$ lidocaine solution. An epitympanic probe (M1024233, GE Healthcare Finland Oy) was inserted according to the product instructions into the right ear and fixed to the lobe using standard surgical tape to prevent displacement. Ten participants additionally used industrial ear protectors (Arton 2200, Emil Lux GmbH \&
Co. KG, Wermelskirchen, Switzerland) to insulate the ear from ambient air. After successful insertion, the probes were connected to an intensive care monitor (Compact Anesthesia Monitor, GE Healthcare Finland Oy).

\section{Protocol}

Probes were placed after at least $30 \mathrm{~min}$ of rest. After placement of the probes in the medical examination office, participants were guided to the first test setting. Measurements were recorded every $5 \mathrm{~s}$ for a total duration of $10 \mathrm{~min}$ for each location (participants were in a seated position for the testing duration). The interval to transfer to the second test setting and commence data recording was between 3 and $5 \mathrm{~min}$. Complete winter clothing including a hat was allowed during measurements at low temperature but was removed during measurements at room temperature.

\section{Data analysis}

Descriptive data are reported as mean \pm standard deviation unless otherwise indicated. The Wilcoxon signedrank test was used to compare (i) $\mathrm{T}_{\text {es }}$ and $\mathrm{T}_{\text {ty }}$ in the same person at a specified duration of exposure and (ii) $\mathrm{T}_{\text {es }}$ or $\mathrm{T}_{\text {ty }}$ in the same person between the first and last measurement. The Wilcoxon-Mann-Whitney test was used to compare $\mathrm{T}_{\text {es }}$ or $\mathrm{T}_{\text {ty }}$ between groups $\mathrm{A}$ and $\mathrm{B}$ and the Pearson coefficient to correlate differences between $\mathrm{T}_{\text {es }}$ or $\mathrm{T}_{\text {ty }}$ in the room and low temperature setting. The Bland-Altman plot and concordance correlation coefficient (CCC) [16] were used to quantify the agreement between $\mathrm{T}_{\mathrm{es}}$ and $\mathrm{T}_{\mathrm{ty}}$. A model to correct $\mathrm{T}_{\text {ty }}$ was developed using a linear regression. The statistical analyses were performed using SPSS software (Version 22.0.0.0, SPSS Inc., Chicago, IL, USA); the Bland-Altman plot and CCC were calculated using MedCalc (Version 9.3.7.0, MedCalc Software, Ostend, Belgium). $P<0.05$ was considered significant.

\section{Results}

There were 31 participants (two females) with mean age $38 \pm 12$ years (range 22-61 years). The ambient air temperature in the room temperature setting was $23.2 \pm$ $0.4{ }^{\circ} \mathrm{C}$ and in the low temperature setting was $-18.7 \pm$ $1.0^{\circ} \mathrm{C}$. In one participant the oesophageal probe was displaced after $5 \mathrm{~min}$ at room temperature and the last 5 min of measurements had to be excluded from the analysis. In one participant the monitor data was not stored and manually recorded measurements were used for the last $4 \mathrm{~min}$ at low temperature.

\section{Measurements at room temperature}

Temperature measurements during testing at room temperature are shown in Fig. 1a. Mean $\mathrm{T}_{\text {es }}$ was $36.8 \pm$ $0.4{ }^{\circ} \mathrm{C}$ at 0 min and $36.8 \pm 0.3{ }^{\circ} \mathrm{C}$ at 9:35 $\min (n=30, p=$ 

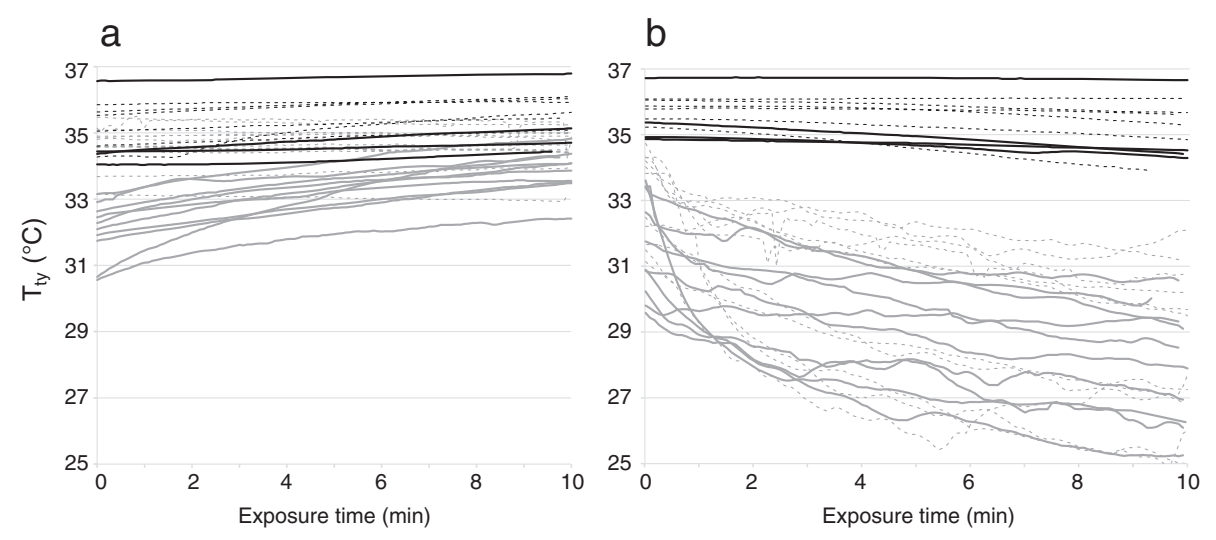

Fig. 1 Epitympanic temperature $\left(T_{\text {ty }}\right)$ at room temperature $\left(\mathbf{a} ; 23.2 \pm 0.4{ }^{\circ} \mathrm{C}\right)$ and low temperature $\left(\mathbf{b} ;-18.7 \pm 1.0^{\circ} \mathrm{C}\right)$ in relation to exposure time in minutes. Data are displayed for group A (solid lines; exposure to low followed by room temperature), group B (dotted lines; exposure to room followed by low temperature), with insulation of the ear (black) and without insulation of the ear (grey)

0.124). Without insulation of the ear, mean $\mathrm{T}_{\text {ty }}$ increased from $33.4 \pm 1.5{ }^{\circ} \mathrm{C}$ at $0 \mathrm{~min}$ to $34.2 \pm 0.8{ }^{\circ} \mathrm{C}$ at $9: 35 \mathrm{~min}$ $(n=21, p=0.004)$. With insulation of the ear (using the ear protector), mean $\mathrm{T}_{\text {ty }}$ increased from $35.0 \pm 0.8^{\circ} \mathrm{C}$ at 0 min to $35.5 \pm 0.7^{\circ} \mathrm{C}$ at $9: 35 \min (n=10, p=0.005)$.

Based on a Bland-Altman plot (Fig. 2), the mean difference between $\mathrm{T}_{\text {ty }}$ without insulation of the ear and $\mathrm{T}_{\mathrm{es}}$ was $2.9{ }^{\circ} \mathrm{C}$ and the correlation was weak $(\mathrm{CCC}=0.03$, $95 \%$ confidence interval $[\mathrm{CI}] 0.00-0.06, n=21)$. The mean difference was less with insulation of the ear $\left(1.5^{\circ} \mathrm{C}\right)$ and the correlation was not significant $(\mathrm{CCC}=0.11,95 \%$ CI $-0.05-0.27, n=10$ ).

In the room temperature setting, $\mathrm{T}_{\mathrm{ty}}$ without insulation of the ear was lower at $0 \mathrm{~min}$ in group A $\left(32.0 \pm 0.9^{\circ} \mathrm{C}\right.$; $n=10)$ compared to $\mathrm{B}\left(34.6 \pm 0.7^{\circ} \mathrm{C} ; n=11, p<0.001\right)$, but was not different with insulation of the ear $(p=0.476)$.

\section{Measurements at low temperature}

Temperature measurements during testing at low temperature are shown in Fig. 1b. Mean $\mathrm{T}_{\mathrm{es}}$ was $36.7 \pm$ $0.4{ }^{\circ} \mathrm{C}$ at 0 min and $36.8 \pm 0.4{ }^{\circ} \mathrm{C}$ at 9:15 $\min (n=31$, $p=0.001$ ). Without insulation of the ear, mean $\mathrm{T}_{\text {ty }}$ decreased from $32.4 \pm 1.6{ }^{\circ} \mathrm{C}$ at $0 \mathrm{~min}$ to $28.5 \pm 2.0{ }^{\circ} \mathrm{C}$ at 9:15 $\mathrm{min}(n=21, p<0.001)$. With insulation of the ear, mean $\mathrm{T}_{\text {ty }}$ decreased from $35.6 \pm 0.6{ }^{\circ} \mathrm{C}$ at $0 \mathrm{~min}$ to $35.2 \pm 0.9{ }^{\circ} \mathrm{C}$ at $9: 15 \min (n=10, p=0.007)$.

Based on a Bland-Altman plot (Fig. 2), the mean difference between $T_{\text {ty }}$ without insulation of the ear and $\mathrm{T}_{\text {es }}$ was $7.2{ }^{\circ} \mathrm{C}$ and the correlation was not significant $(\mathrm{CCC}=0,95 \% \mathrm{CI}-0.01-0.01, n=21)$. The mean difference was less with insulation of the ear $\left(1.3{ }^{\circ} \mathrm{C}\right)$, which was similar to the mean difference at room temperature $\left(1.5{ }^{\circ} \mathrm{C}\right)$. The correlation between $\mathrm{T}_{\text {ty }}$ with insulation of the ear and $\mathrm{T}_{\mathrm{es}}$ was not significant $(\mathrm{CCC}=0.18$, $95 \%$ CI $-0.02-0.37, n=10$ ).
In the low temperature setting, $\mathrm{T}_{\mathrm{ty}}$ without insulation of the ear was lower at $0 \mathrm{~min}$ in group $\mathrm{A}\left(31.5 \pm 1.4{ }^{\circ} \mathrm{C}\right.$; $n=10)$ compared to $\mathrm{B}\left(33.3 \pm 1.3{ }^{\circ} \mathrm{C} ; n=11, p=0.008\right)$, but was not different with insulation of the ear $(p=0.352)$.

\section{Individual variability in temperature}

To understand the influence of inter-individual variability, the difference between $\mathrm{T}_{\text {ty }}$ and $\mathrm{T}_{\text {es }}$ at $3 \mathrm{~min}$ at room temperature was correlated to the difference between $\mathrm{T}_{\text {ty }}$ and $\mathrm{T}_{\mathrm{es}}$ at $3 \mathrm{~min}$ at low temperature for each individual. We chose $3 \mathrm{~min}$ to reduce the variability seen in some measurements in the first minutes after exposure. The measurements were correlated, suggesting that individuals with a large deviation between $\mathrm{T}_{\text {ty }}$ and $\mathrm{T}_{\mathrm{es}}$ in one setting also had a large deviation in the other setting. The correlation was stronger with insulation of the ear $(r=0.907, n=10, p<0.001)$ compared to without $(r=0.446, n=21, p=0.043)$.

\section{Model for predicting core temperature}

$\mathrm{T}_{\text {ty }}$ was corrected $\left(\mathrm{T}_{\text {ty_c }}\right)$ using a linear regression model to predict $\mathrm{T}_{\mathrm{es}}$ from $\mathrm{T}_{\mathrm{ty}}$ at $3 \mathrm{~min}$. The model at room temperature was $T_{t y_{-} c}=32.32+0.134 * T_{t y}$ without insulation of the ear and $T_{t y_{-} c}=26.394+0.295 * T_{t y}$ with insulation. The model at low temperature was $T_{t y_{-} c}=$ $37.025-0.008 * T_{t y}$ without insulation and $T_{t y_{-} c}=17.15+$ $0.55 * T_{t y}$ with insulation. Based on a Bland-Altman plot (Fig. 3), the differences between $\mathrm{T}_{\text {ty c }}$ and $\mathrm{T}_{\text {es }}$ were correlated at room temperature without insulation $(\mathrm{CCC}=$ $0.446,95 \%$ CI $0.129-0.681, n=21)$ and at low temperature with insulation $(\mathrm{CCC}=0.659,95 \%$ CI 0.172 $0.887, n=10)$; at room temperature with insulation the correlation was not significant $(\mathrm{CCC}=0.389,95 \%$ CI $-0.107-0.730, n=10)$. At low temperature without insulation, Fig. 3c shows that model correction was not 

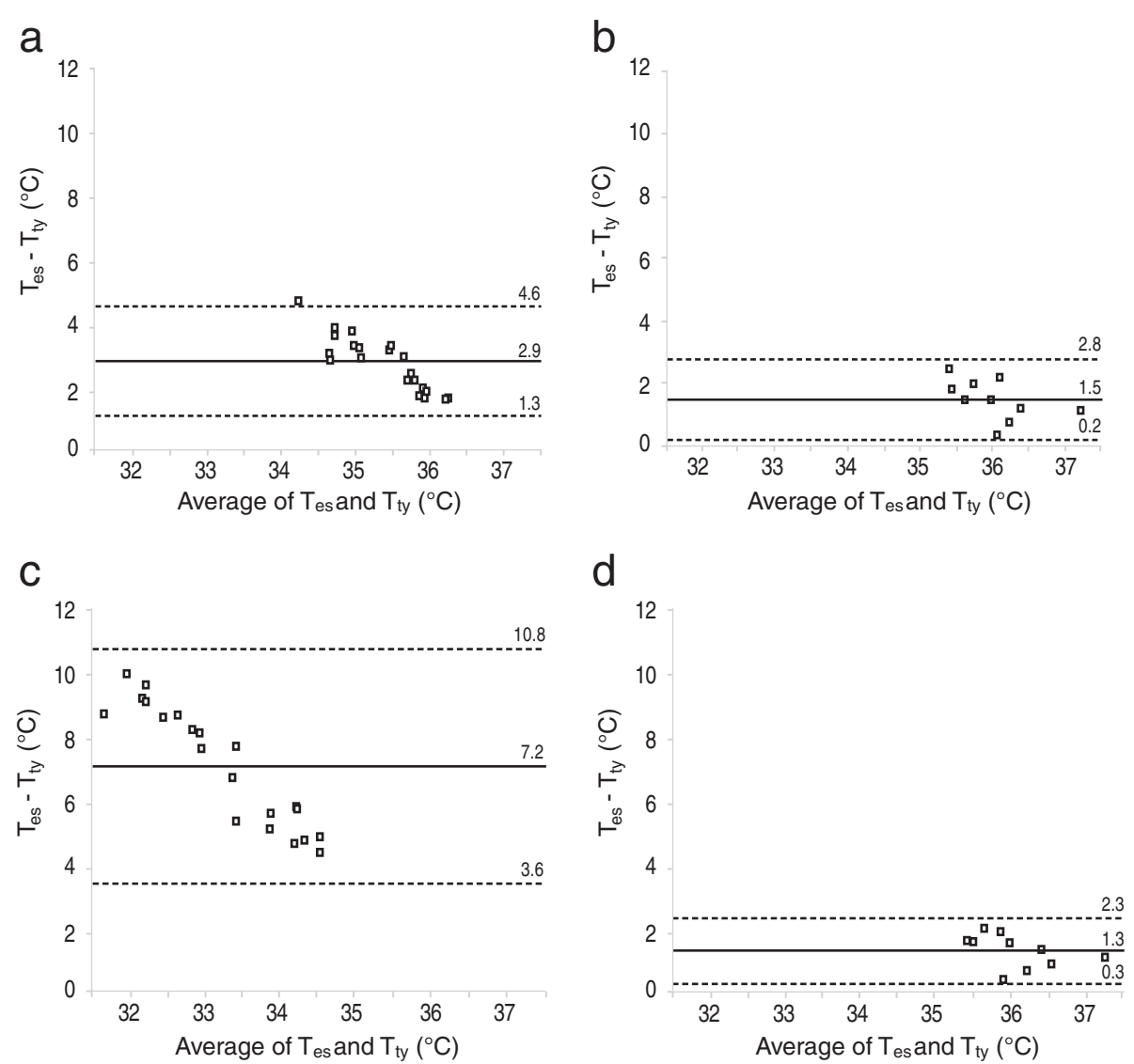

Fig. 2 Bland-Altman plots of individual data for mean $T_{\text {es }}$ and $T_{\text {ty }}$ at room temperature (a, without insulation of the ear; $\mathbf{b}$, with insulation) and low temperature (c, without insulation of the ear; $\mathbf{d}$, with insulation). The solid line is the mean of differences and the dashed lines are the limits of agreement (mean \pm 1.96 standard deviation)

effective and measurements were not correlated (CCC $=$ 0.009, 95 \% CI -0.036-0.054, $n=21$ ).

\section{Discussion}

We report the influence of low ambient temperature and individual factors on temperature measured epitympanically using a thermistor-based probe. We found a deviation from the reference $\mathrm{T}_{\text {core }}$ that was markedly reduced with insulation of the ear from ambient air using an ear protector. We also propose a model to correct $\mathrm{T}_{\text {ty. }}$ Nevertheless, inter-individual variability remained and variations in probe placement likely account for some of the variability.

\section{Influence of ambient temperature}

Epitympanic measurements were influenced by ambient temperature. During exposure to room temperature, mean $\mathrm{T}_{\text {ty }}$ increased by $0.8^{\circ} \mathrm{C}$, whereas it decreased by $3.9^{\circ} \mathrm{C}$ during exposure to low temperature. Similarly, mean deviation from $\mathrm{T}_{\text {es }}$ was $>50 \%$ higher in the low temperature setting compared to the room temperature setting. However, it is interesting that the difference to $\mathrm{T}_{\mathrm{es}}$ in our data was reduced with simple external insulation with an ear protector; with insulation the mean difference to $\mathrm{T}_{\mathrm{es}}$ was reduced by $52 \%$ in the room temperature setting (difference of 2.9 to $1.5{ }^{\circ} \mathrm{C}$ ) and by $82 \%$ in the low temperature setting (7.2 to $1.3{ }^{\circ} \mathrm{C}$; Fig. 2). This suggests that the ear cover limits exchange of ambient air, thus creating a "microclimate" in the ear canal, though the influence of ambient temperature on $\mathrm{T}_{\text {ty }}$ was not completely removed. Moreover, previous studies of $\mathrm{T}_{\text {ty }}$ that also insulated the ear or ear canal reported that measurements required several minutes to stabilize $[5,12,13]$, even if an external device was used to heat the ear protector [12]. In our study, $\mathrm{T}_{\text {ty }}$ without insulation of the ear did not stabilize and showed rapid and constant decreases over $10 \mathrm{~min}$ in low ambient temperature. This explains the differences in $\mathrm{T}_{\text {ty }}$ at baseline between group $\mathrm{A}$ and $\mathrm{B}$-for example, in the room temperature setting mean $\mathrm{T}_{\mathrm{ty}}$ at $0 \mathrm{~min}$ was lower in group A than B because they had already been exposed to low ambient temperature and adaptation to the warmer temperature was still occurring in the first minutes. 

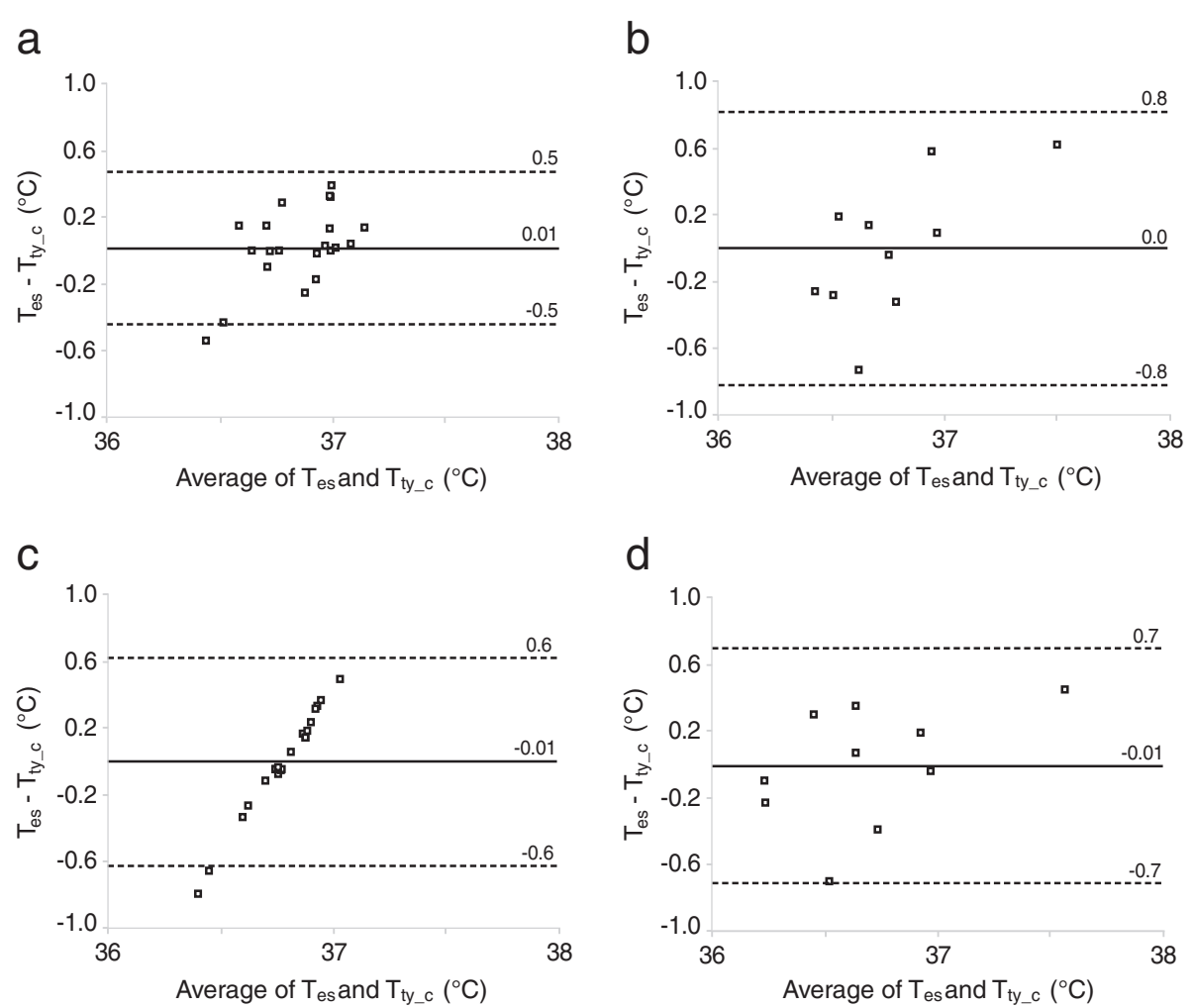

Fig. 3 Bland-Altman plots of individual data for $T_{\text {es }}$ and $T_{\text {ty }}$ c at room temperature (a, without insulation of the ear; $\mathbf{b}$, with insulation) and low temperature (c, without insulation of the ear; $\mathbf{d}$, with insulation). The solid line is the mean of differences and the dashed lines are the limits of agreement (mean \pm 1.96 standard deviation). $T_{\text {ty_c }}$ are corrected values of $T_{\text {ty }}$ at 3 min derived from a linear regression model to predict $T_{e s}$

\section{Inter-individual variability}

We found that the degree of deviation of $\mathrm{T}_{\mathrm{ty}}$ from $\mathrm{T}_{\mathrm{es}}$ in both ambient air settings was different between individuals, i.e. individuals with a large deviation in one setting also had a large deviation in the other setting. This is partially due to differences in placement of the probe. Temperature in the ear canal seems to decrease with increasing distance from the tympanic membrane $[17,18]$, and thus $\mathrm{T}_{\text {ty }}$ will be less reflective of $\mathrm{T}_{\text {core }}$ with increasing distance. The distance between the sensor and the tympanic membrane will vary slightly between individuals because of differences in anatomy (length, width, shape) that affect insertion depth. Additionally, there may be other unknown physiological factors such as individual differences in the vascular anatomy of the ear and thermal conductivity and perfusion of the tissues that could influence the absolute difference between $\mathrm{T}_{\text {ty }}$ and $\mathrm{T}_{\text {core }}$ in an individual.

\section{Practical implications}

Measuring $\mathrm{T}_{\text {core }}$ is the only way to accurately assess the severity of hypothermia. There are other commonly used scales to stage hypothermia based on clinical signs and symptoms, but these are not always reliable since there are differences in consciousness among patients at a given $\mathrm{T}_{\text {core }}$ [19]. Patients with mild hypothermia $\left(\mathrm{T}_{\text {core }}\right.$ 35 to $32{ }^{\circ} \mathrm{C}$ ) can be treated in the field if they are uninjured or transported to the closest hospital if in-field rewarming is not possible, whereas patients with moderate hypothermia $\left(\mathrm{T}_{\text {core }}<32{ }^{\circ} \mathrm{C}\right.$ ) should be transported to the most appropriate hospital on the basis of cardiac stability [7]. The results of our study show a large difference $\left(7.2{ }^{\circ} \mathrm{C}\right)$ between mean $\mathrm{T}_{\text {ty }}$ and $\mathrm{T}_{\text {core }}$ at low temperature, which in practical terms could lead to wrong triage and transport even of normothermic patients. These results also suggest that $\mathrm{T}_{\text {ty }}$ without insulation of the ear does not stabilize within $10 \mathrm{~min}$, and thus is impractical for applications that require rapid measurement and/or accurate monitoring of changes in $\mathrm{T}_{\text {core }}$.

The models to correct $T_{\text {ty }}$ seem to give a valid estimation of $\mathrm{T}_{\mathrm{es}}$ for measurements at room temperature without insulation of the ear and at low temperature with insulation. It was unexpected that the correlation between $\mathrm{T}_{\text {ty_c }}$ and $\mathrm{T}_{\mathrm{es}}$ at room temperature with insulation was low and non-significant, though this is probably due to the small sample size $(n=10)$. In comparison to these three conditions, it was not possible to create a realistic model for measurements at low temperature without 
insulation. Thus in order to reliably predict $\mathrm{T}_{\text {core }}$ from epitympanic temperature, modification of currently available devices (i.e. ear cover) and development of an appropriate model to correct for ambient temperature may be necessary. Thermistor-based $\mathrm{T}_{\text {ty }}$ probes are noninvasive and easy to use and could be used with standard patient monitors. This would also allow continuous monitoring of ECG and $\mathrm{T}_{\text {core }}$, as recommended in international guidelines for pre-hospital management of accidental and therapeutic hypothermia [7].

\section{Limitations and further research}

The results are based on measurements in healthy, normothermic volunteers at rest in the two reported ambient temperatures and may not be applicable for other populations (e.g. patients in cardiac arrest, trauma) or ambient conditions. The models to correct $\mathrm{T}_{\mathrm{ty}}$ should be validated with a larger sample size. The lack of correlation between $\mathrm{T}_{\mathrm{es}}$ and $\mathrm{T}_{\mathrm{ty}}$ (or $\mathrm{T}_{\text {ty_c }}$ ) at room temperature with insulation may be due to the small sample size $(n=$ 10). Further investigations are needed to understand if models could account for other factors characteristic of the prehospital environment such as rapidly changing conditions and wind.

\section{Conclusion}

Epitympanic temperature measurements are influenced by ambient temperature and deviate from $T_{e s}$ at room temperature and low ambient temperature. Insulating the ear with standard industrial ear protectors markedly reduced the difference between $\mathrm{T}_{\text {ty }}$ and $\mathrm{T}_{\text {es }}$ and improved the stability of measurements over the testing duration. The use of models to correct $\mathrm{T}_{\text {ty }}$ may be possible, but results should be validated in larger studies.

\section{Ethics, consent and permissions}

The study was approved by the Ethics Committee of the Regional Hospital of Bolzano, Italy. Written informed consent was obtained from all participants prior to participation in the study.

\section{Competing interests}

The authors declare that they have no competing interests.

\section{Authors' contributions}

GS, EP and HB conceived and designed the study. GS and HB supervised the study and data collection. TDC provided statistical advice on study design and analyzed the data. GS, EP, GP, GA, NÜ, GH, BR and GR assisted with data collection and analysis. GS and EP drafted the manuscript and all authors read and approved the final manuscript.

\section{Author details}

${ }^{1}$ EURAC Institute of Mountain Emergency Medicine, Bolzano, Italy.

${ }^{2}$ Department of Anaesthesiology and Critical Care Medicine, Innsbruck Medical University, Innsbruck, Austria. ${ }^{3}$ Department of Otolaryngology, General Hospital of Bressanone, Bressanone, Italy. ${ }^{4}$ Department of Anesthesiology and Critical Care Medicine, General Hospital of Silandro, Silandro, Italy. ${ }^{5}$ Department of Anaesthesiology, Marienklinik, Bolzano, Italy.
${ }^{6}$ Department of Anaesthesiology and Critical Care Medicine, General Hospital of Bressanone, Bressanone, Italy.

Received: 22 April 2015 Accepted: 28 October 2015

Published online: 05 November 2015

\section{References}

1. Strapazzon G, Procter E, Paal P, Brugger H. Pre-hospital core temperature measurement in accidental and therapeutic hypothermia. High Alt Med Biol. 2014;15(2):104-11.

2. Benzinger TH. On physical heat regulation and the sense of temperature in man. Proc Natl Acad Sci U S A. 1959;45(4):645-59.

3. Brinnel $\mathrm{H}$, Cabanac M. Tympanic temperature is a core temperature in humans. J Therm Biol. 1989;14(1):47-53.

4. Mariak Z, White MD, Lyson T, Lewko J. Tympanic temperature reflects intracranial temperature changes in humans. Pflugers Arch. 2003;446(2):279-84.

5. Walpoth BH, Galdikas J, Leupi F, Muehlemann W, Schlaepfer P, Althaus U. Assessment of hypothermia with a new "tympanic" thermometer. J Clin Monit. 1994;10(2):91-6.

6. Shin J, Kim J, Song K, Kwak Y. Core temperature measurement in therapeutic hypothermia according to different phases: comparison of bladder, rectal, and tympanic versus pulmonary artery methods. Resuscitation. 2013;84(6):810-17.

7. Brown DJ, Brugger H, Boyd J, Paal P. Accidental hypothermia. N Engl J Med. 2012;367(20):1930-38.

8. Brugger H, Durrer B, Elsensohn F, Paal P, Strapazzon G, Winterberger E, et al. Resuscitation of avalanche victims: evidence-based guidelines of the international commission for mountain emergency medicine (ICAR MEDCOM): intended for physicians and other advanced life support personnel. Resuscitation. 2013;84(5):539-46.

9. Oberhammer R, Beikircher W, Hörmann C, Lorenz I, Pycha R, Adler-Kastner L, et al. Full recovery of an avalanche victim with profound hypothermia and prolonged cardiac arrest treated by extracorporeal re-warming. Resuscitation. 2008;76(3):474-80.

10. Koppenberg J, Brugger H, Esslinger A, Albrecht R. Life-saving air supported avalanche mission at night in high alpine terrain. Anaesthesist. 2012:61(10):892-900.

11. Strapazzon G, Nardin M, Zanon P, Kaufmann M, Kritzinger M, Brugger H. Respiratory failure and spontaneous hypoglycemia during noninvasive rewarming from 24.7 degrees $C$ (76.5 degrees F) core body temperature after prolonged avalanche burial. Ann Emerg Med. 2012;60(2):193-96.

12. Keatinge WR, Sloan RE. Deep body temperature from aural canal with servo-controlled heating to outer ear. J Appl Physiol. 1975;38(5):919-21.

13. Teunissen LP, de Haan A, de Koning JJ, Clairbois HE, Daanen HA. Limitations of temperature measurement in the aural canal with an ear mould integrated sensor. Physiol Meas. 2011;32(9):1403-16.

14. Livingstone SD, Grayson J, Frim J, Allen CL, Limmer RE. Effect of cold exposure on various sites of core temperature measurements. J Appl Physiol Respir Environ Exerc Physiol. 1983;54(4):1025-31.

15. Hu EW, Wakamatsu BK, Smith DD. Emergency procedures. In: Roppolo L, Davis D, Kelly S, Rosen P, editors. Emergency medicine handbook; critical concepts for clinical practice. Edinburgh: Elsevier Mosby; 2007. p. 1223-75.

16. Lin LI. A concordance correlation coefficient to evaluate reproducibility. Biometrics. 1989;45(1):255-68.

17. Procter E, Strapazzon G, Rilk C, Überbacher N, Brugger H. Temperature gradient in the inner ear canal and implications for epitympanic temperature measurement. High Alt Med Biol. 2014;15:A-281.

18. Cooper KE, Cranston WI, Snell ES. Temperature in the external auditory meatus as an index of central temperature changes. J Appl Physiol. 1964;19:1032-35.

19. Pasquier M, Zurron N, Weith B, Turini P, Dami F, Carron PN, et al. Deep accidental hypothermia with core temperature below $24{ }^{\circ} \mathrm{C}$ presenting with vital signs. High Alt Med Biol. 2013;15(1):58-63. 